\title{
Epistaxis in dental and maxillofacial practice: a comprehensive review
}

\author{
George Psillas ${ }^{1}$, Grigorios Georgios Dimas ${ }^{2}$, Despoina Papaioannou ${ }^{3}$, \\ Christos Savopoulos ${ }^{2}$, Jiannis Constantinidis ${ }^{1}$ \\ ${ }^{1} 1$ st Academic ENT Department, ${ }^{2} 1$ st Propedeutic Department of Internal Medicine, and ${ }^{3}$ School of Dentistry, \\ Aristotle University of Thessaloniki, AHEPA Hospital, Thessaloniki, Greece
}

\begin{abstract}
J Korean Assoc Oral Maxillofac Surg 2022;48:13-20)
The lifetime incidence of epistaxis in dental and maxillofacial practice has been reported to be as high as $60 \%$ and can be caused by dental implant placement, Le Fort I osteotomy, intranasal supernumerary tooth, odontogenic tumors, blood disorders and maxillofacial trauma. Most epistaxis cases are minor and easily managed with direct compression on the nares for 10 minutes. For more significant or recurrent epistaxis, other techniques might include electrocautery, anterior or posterior nasal packing, or Foley catheter balloon. For patients with refractory epistaxis, cauterization of the sphenopalatine artery under endonasal endoscopy or embolization of the internal maxillary artery should be performed. Epistaxis control is required in patients diagnosed with inherited or acquired bleeding disorders or with drug-induced coagulopathies during dental procedures. In these cases, hemostatic system adjustment and hemostasis achieved by local and adjunctive methods are required. Dentists and maxillofacial surgeons must be aware that the nasal cavity is a potential source of perioperative hemorrhage. Depending on the invasiveness of the dental intervention, preoperative involvement of the hematologist and cardiologist is usually necessary to reverse anticoagulation or to cease anticoagulant therapy.
\end{abstract}

Key words: Orthognathic surgery, Dental implants, Epistaxis, Maxilla, Blood coagulation

[paper submitted 2021. 1. 24 / revised 2021. 4. 5 / accepted 2021. 4. 20]

\section{Introduction}

Epistaxis is a relatively frequent symptom, with a lifetime prevalence of approximately $60 \%$ in the general population ${ }^{1}$. Among postoperative complications, epistaxis following dental or maxillofacial surgery is uncommon ${ }^{2}$. However, due potential significant morbidity, dentists should be aware of the potential causes of epistaxis related to dental and maxillofacial procedures and be informed about basic treatments.

Most epistaxis cases $(\sim 90 \%)$ originate from the anterior nasal septum, supplied by Kiesselbach's plexus ${ }^{3}$. These are branches of the internal maxillary artery, the sphenopalatine artery, and the anterior ethmoidal artery. The posterior nasal septum and the lateral nasal wall receive their vascular supply

\section{George Psillas}

1st Academic ENT Department, Aristotle University of Thessaloniki, AHEPA Hospital, No. 1, Stilponos Kyriakidi St., Thessaloniki 54636, Greece

TEL: +30-2310-994-768

E-mail:psill@otenet.gr

ORCID: https://orcid.org/0000-0003-3509-6519

(c) This is an open-access article distributed under the terms of the Creative Commons Attribution Non-Commercial License (http://creativecommons.org/ licenses/by-nc/4.0/), which permits unrestricted non-commercial use, distribution, and reproduction in any medium, provided the original work is properly cited.

Copyright (C) 2022 The Korean Association of Oral and Maxillofacial Surgeons. from the sphenopalatine artery and terminal branches of the internal maxillary artery ${ }^{3}$, which are the sources of posterior nasal bleeding.

The literature on epistaxis and its association with dental and maxillofacial interventions is limited. Thus, we reviewed specific management and treatment modalities to help dentists make decisions for such cases.

\section{Materials and Methods}

A literature search of PubMed, Embase, CENTRAL, and Cochrane Library databases was performed, focusing on studies published until April 2020. We combined the MeSH (Medical Subject Headings) terms "epistaxis," "nose bleeding," and "hemorrhage" with "dental interventions," "dental implants," "Le Fort osteotomy," "supernumerary tooth," "blood disorders," "odontogenic tumors," and "maxillofacial trauma." Results were checked for duplicates, and titles, abstracts, and full texts were evaluated to exclude irrelevant articles. We finally included 48 studies in our review. Studies were included regardless of type (review articles, original research, case reports). The inclusion criteria were determined 
according to the scope of study and data analysis: articles analyzing the diagnosis, source, and treatment approaches of epistaxis; etiology of nasal hemorrhage and selection of types of interventions for the sinonasal and oral areas; no gender or age restrictions. Article exclusion criteria were finite element analysis studies, animal studies, and in vitro studies.

\section{Results}

\section{Etiology}

\section{1) Dental implants}

The edentulous posterior maxillary is a challenging region for implant placement due to pneumatization of the maxillary sinus cavity, which can lead to lack of cortical bone height and resorption of the alveolar ridge ${ }^{4}$. The thick cortical bone of the maxillary sinus prevents direct spread of odontogenic infections into the maxilla bone. Nevertheless, the alveolar bone can become thinner due to aging, leaving only the Schneiderian membrane between the sinus and the mouth ${ }^{5}$. In this context, perforation of the Schneiderian membrane remains a potential complication during implant surgeries in approximately $15.7 \%$ of $\operatorname{cases}^{6}$, and bleeding in the maxilla can appear as epistaxis.

Bleeding in the maxilla is more likely when the bone covering the tooth roots is $\operatorname{thin}^{7,8}$; in cases of extensive sinus pneumatization, the alveolar process thins, exposing the alveolar canal with vessels to stimulating forces, such as dental implant surgery, with risk of massive bleeding ${ }^{8}$. Epistaxis was not a frequently reported complication after dental implant surgery ( $8.8 \%$ of cases).(Table 1) Epistaxis is more specifically observed when dentists place a part of a dental implant into the maxillary sinus to increase the height of the crestal bone $^{9-11}$.(Table 1) In these studies, patients experienced selflimiting nose bleeds during the immediate postoperative period. However, Hong and $\mathrm{Mun}^{8}$ reported a case of dental implants in which a 54-year-old female patient appeared with serious nasal bleeding; the bleeding was so perfuse despite anterior and posterior nasal packing that the woman was eventually treated under general anesthesia. It is possible that the cause of the bleeding was injury to the posterior superior alveolar artery (Fig. 1) because the dental implant seemed to stick out toward the maxillary sinus, which was covered by Schneiderian's membrane. Similarly, in their study, Bae et al. ${ }^{12}$ placed dental implants simultaneous with sinus floor elevation via either an osteotome or a reamer, and they recorded epistaxis as a complication in $6.7 \%$ (osteotome) and $5 \%$ (reamer) of patients, all of which resolved in the following days.(Table 1)

\section{2) Le Fort I osteotomy}

The Le Fort I maxillary osteotomy is a common maxillofacial surgery used to fix many malocclusion and maxillofacial abnormalities. Complications are rare, but epistaxis can occur when the pterygoid plates are separated from the maxilla. The involved vessels usually include the terminal branches of the internal maxillary artery, especially the descending palatine or sphenopalatine arteries, the posterior superior alveolar artery, and the pterygoid venous plexus ${ }^{13,14}$. The descending palatine artery and the posterior superior alveolar artery (Fig. 1) can be

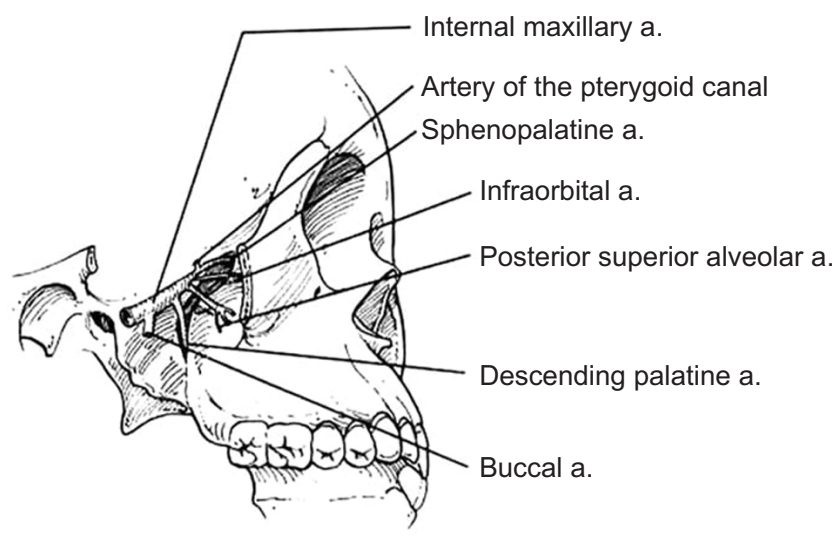

Fig. 1. Anatomical diagram of the internal maxillary artery and its branches (sources of posterior epistaxis). (a.: artery)

George Psillas et al: Epistaxis in dental and maxillofacial practice: a comprehensive review. J Korean Assoc Oral Maxillofac Surg 2022

Table 1. Studies reporting epistaxis as complication after dental-implant surgery

\begin{tabular}{|c|c|c|c|c|}
\hline Study & Article type & Technique & $\begin{array}{l}\text { Total No. } \\
\text { of patients }\end{array}$ & $\begin{array}{l}\text { No. of patients } \\
\text { with epistaxis }\end{array}$ \\
\hline Nooh $^{9}$ & Retrospective study & Sinus lift with membrane perforation & 56 & 7 \\
\hline Kim et al. ${ }^{10}$ & Retrospective study & Sinus membrane penetration & 39 & 3 \\
\hline Shihab $^{11}$ & Retrospective study & Sinus lift with membrane perforation & 35 & 3 \\
\hline \multirow[t]{2}{*}{ Bae et al. $^{12}$} & Retrospective study & Reamer-mediated & 40 & 2 \\
\hline & & Osteotome-mediated & 45 & 3 \\
\hline Hong and Mun ${ }^{8}$ & Case report & Dental implantation & 1 & 1 \\
\hline
\end{tabular}

George Psillas et al: Epistaxis in dental and maxillofacial practice: a comprehensive review. J Korean Assoc Oral Maxillofac Surg 2022 
injured during Le Fort I osteotomy because of their location. Severing the posterior superior alveolar artery usually does not result in remarkable hemorrhaging unless it is a largediameter vessel ${ }^{13}$. The descending palatine artery is more susceptible to damage during Le Fort I osteotomy because there is a possibility of vessel splitting when the surgeon separates the pterygomaxillary or the nasal wall ${ }^{14}$. Mehra et al. ${ }^{14}$ reported that the descending palatine artery is most likely to bleed after surgically-assisted rapid palatal expansion (SARPE) because this artery is injured by bone fractures.

Primary sources of epistaxis after Le Fort I osteotomies are the anterior, posterior, or both parts of the nasal cavity, and epistaxis usually occurs within the first 10 days after surgery ${ }^{15-19}$.(Table 2) Intubation and removal of the nasal mucosa from the nasal floor require special manipulation to avoid an isolated anterior ${ }^{20}$. Usually, posterior damage of an artery leads to bleeding from both nares ${ }^{20}$. The bleeding is not very serious and usually lasts 1 to 2 days. However, recurrent epistaxis has been noted in patients 1 to 8 weeks after orthognathic surgery, in which the presence of pseudoaneurysm was suspected during orthognathic interventions ${ }^{18,19,21}$, wherein an incomplete injury to one or more vessel-wall layers causes hemorrhaging in the surrounding tissue, leading to hematoma formation. Subsequent expansion of a hematoma due to arterial pressure can result in increased leakage and rupture ${ }^{19,21}$. According to a review ${ }^{22}$ of 19 patients with ruptured pseudoaneurysms following Le Fort I osteotomy, initial nasal bleeding began an average of 17.3 \pm 14.3 days (range, 3-62 days) following surgery. The majority of patients $(67 \%)$ had multiple episodes of epistaxis after an initial period of minimal and self-limited epistaxis ${ }^{22}$. The affected vessels were the internal maxillary artery (38.9\%), descending palatine artery $(16.7 \%)$, sphenopalatine artery $(38.9 \%)$, and internal carotid artery $(5.6 \%)^{22}$.

\section{3) Intranasal supernumerary tooth}

Intranasal tooth eruption is an uncommon event, with incidence from $0.1 \%$ to $1 \%$ in the general population ${ }^{23}$. This can be either an extra tooth or a diversion of normal dentition (deciduous/permanent). Intranasal teeth present mainly in children, and are often asymptomatic, but can cause a variety of symptoms (nasal discharge, unilateral nasal obstruction, foul smell, anosmia, headaches), including recurrent epistaxis $^{24}$. Epistaxis was reported to occur in young patients once or twice a month for two ${ }^{25}$ or three years ${ }^{26}$ during the period of tooth eruption into the nasal cavity.

Supernumerary nasal teeth are easily recognized from their small crowns in contrast with the root and the conical or tuberculate shape ${ }^{27}$. They grow in a vertical, horizontal, or inverted position, and they have been observed in the palate as extra teeth or can grow into the nasal cavity ${ }^{27}$. No hypotheses about their eruption are widely accepted. One view highlights faults during the interactions between the epithelia and mesenchym. There are also scientists who emphasize errors during the migration of neural crest derivatives to reach the jaw bones $^{25}$.

Clinically, intranasal teeth present as an ivory white mass most often found on the floor of the nose, relatively anteriorly inside the nostril ${ }^{23,28}$; sometimes, intranasal teeth can be completely covered by nasal mucosa or granulation tissue $^{24,25}$. Intranasal teeth can be found accidentally as a dense radiopaque shadow on panoramic radiograph ${ }^{24}$; however, computed tomography (CT) is more useful for showing supernumerary intranasal teeth ${ }^{26}$. Clinicians should distinguish an ectopic nasal tooth from foreign bodies, odontomas, rhinoliths, granulomatous infections, and tumors ${ }^{28}$.

\section{4) Dental care in patients with blood disorders}

Milam and Copper $^{29}$ reported a case of prolonged epistaxis after dental extractions of the upper first and second molars

Table 2. Studies reporting epistaxis as a complication after Le Fort osteotomy

\begin{tabular}{|c|c|c|c|c|c|c|}
\hline Study & Article type & $\begin{array}{l}\text { No. of } \\
\text { patients }\end{array}$ & $\begin{array}{c}\text { Age } \\
\text { group (yr) }\end{array}$ & Surgical approach & $\begin{array}{l}\text { No. of } \\
\text { patients with } \\
\text { epistaxis }\end{array}$ & $\begin{array}{c}\text { Postoperative onset } \\
\text { of epistaxis }\end{array}$ \\
\hline Williams et al. ${ }^{15}$ & Retrospective study & 120 & $22-39$ & SARPE & 7 & 1 hour to 7 days \\
\hline Lanigan et al. ${ }^{13}$ & Questionnaire & NM & $18-23$ & Le Fort I osteotomy & 5 & 18 hours to 10 days \\
\hline de Mol van Otterloo et al. ${ }^{16}$ & Retrospective study & 410 & NM & Le Fort I osteotomy, SARPE & 3 & Several days \\
\hline Eshghpour et al. ${ }^{17}$ & Prospective study & 114 & $18-30$ & Le Fort I osteotomy & 2 & First 24 hours \\
\hline Avelar et al. ${ }^{18}$ & Case report & 1 & 20 & Le Fort I osteotomy & 1 & 9 weeks \\
\hline Park et al. ${ }^{19}$ & Case report & 1 & 30 & Le Fort I osteotomy & 1 & 3 weeks \\
\hline Mehra et al. ${ }^{14}$ & Case report & 1 & 25 & SARPE & 1 & 11 days \\
\hline Solomons and Blumgart $^{2}$ & Case report & 1 & 20 & Le Fort I osteotomy & 1 & One month \\
\hline
\end{tabular}

(NM: not mentioned, SARPE: surgically-assisted rapid palatal expansion)

George Psillas et al: Epistaxis in dental and maxillofacial practice: a comprehensive review. J Korean Assoc Oral Maxillofac Surg 2022 
in a 50-year-old patient with history of chronic hemodialysis. During surgery, an oroantral fistula was noted. Thus, a mucoperiosteal flap was raised, and good hemostasis was achieved. Thirty minutes after surgery, epistaxis from the right nostril and the right puncta developed after the maxillary sinus filled with blood. Within 24 hours, epistaxis subsided following nasal packing, without further incidence. Increased activity of prostaglandin (prostacyclin) with platelet antiaggregatory properties following hemodialysis was possibly responsible for epistaxis onset ${ }^{29}$.

However, epistaxis can exist prior to dental procedures, and dentists should know the effects of bleeding disorders on patient management, especially in invasive dental treatments. Bleeding disorders such as vascular defects (scurvy, purpura, hereditary hemorrhagic telangiectasia [Rendu-Osler-Weber syndrome]), platelet defects (quantitative or qualitative), or coagulation disorders (inherited or acquired, such as hemophilia A or B and Willebrand's disease) are conditions with high risk of postoperative bleeding ${ }^{30}$. To prevent an episode of epistaxis, the medical history of each patient should be reviewed. Patients also might have undiagnosed hemostasis problems. Clinicians should ask their patients about bleeding episodes after surgeries or injuries, impulsive bleeding, or serious bleeding after dental extractions. Dentists must know the patient's family history and their drug list (anticoagulants or antiplatelet therapy). Clinical manifestations of inherited bleeding disorders (e.g., hemophilia) are multiple purpura or ecchymoses of the skin, muscle (hematomas), or joints (hemarthrosis) and gingival or wound bleeds ${ }^{30,31}$. Blood counts and clotting tests (platelet count, prothrombin times) should also be carried out.

\section{5) Odontogenic tumors}

Very few case reports for odontogenic tumors have referred to epistaxis as a symptom. Virupakshappa et al. ${ }^{32}$ described an adenomatoid odontogenic tumor in a 20-year-old female patient who appeared with left epistaxis, associated with slow, progressive facial swelling and pain on the left half of her face. After surgical management of the tumor, swelling and epistaxis resolved. Ameloblastoma, an aggressive neoplasm in the mandible or maxilla, was reported for a 61-yearold white man presenting with unilateral nasal obstruction with long-term epistaxis after extension of the tumor into the nose $\mathrm{e}^{33}$. The patient was treated with removal of the tumor and the medial wall of the maxilla.
6) Maxillofacial trauma

In severe midface trauma, epistaxis usually occurs immediately after facial injury, including Le Fort II and III fractures $^{34}$. Nasal bone fractures usually result in minor epistaxis, which resolves spontaneously. Trauma to the nasoethmoidal complex could be responsible for severe and persistent epistaxis $^{35}$. Epistaxis caused by intrusive luxation of the permanent teeth, such as an upper maxillary tooth into the nasal cavity, is rare ${ }^{36}$. An 11-year-old male injured his maxilla during a fall ${ }^{36}$, and a fracture of the maxillary alveolar bone with an intrusive luxation of the right central incisor was found. The injury penetrated the floor of the nasal cavity causing epistaxis. Under local anesthesia, surgical (not orthodontic) repositioning of the incisor and bone segment was performed, with subsequent fixation using titanium micromesh and screws. No serious symptoms were noticed during a 1.5-year follow-up ${ }^{36}$.

\section{Therapeutic approaches}

Epistaxis treatment varies according to bleeding severity and type. If the bleeding is minor, the patient should lean forward to reduce blood swallowing or aspiration and continuously hold pressure on the nares to the cartilaginous portion of the nose just below the nasal bones for 10 minutes to achieve hemostasis. If bleeding persists or is more serious, the source site should be identified to determine whether the epistaxis is anterior or posterior. For anterior epistaxis, electrocautery is recommended directly on the anterior part of the nasal septum, which contains the Kiesselbach's plexus of vessels. When cautery fails to achieve adequate hemostasis, anterior nasal packing will need to be inserted (Fig. 2) and remain in place for 48 hours $^{1,3}$. Posterior epistaxis is suspected when the bleeding is excessive, bilateral, or accompanied by hematemesis or hemoptysis. Posterior nasal packing is indicated using a Foley catheter balloon (Fig. 3), which is inserted under local anesthesia on the bleeding side, while anterior packing is performed on the contralateral side. The Foley catheter is inflated with up to $10 \mathrm{~mL}$ of normal saline until no blood is observed in the pharynx. Administration of systemic antibiotics is recommended while anterior and posterior packing are maintained $^{3,37}$. In cases of severe intractable epistaxis with repeated failure of packing insertions, cauterization-clipping of the sphenopalatine artery following endonasal endoscopy is performed under general anesthesia ${ }^{38}$, at which time, bleeding sites can be cauterized, spurs can be removed, and a deviated septum can be straightened. Another valuable tool to control 


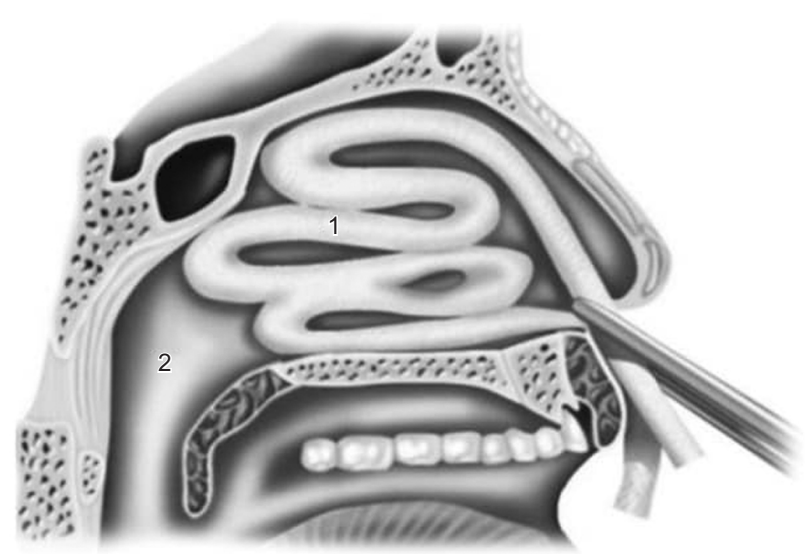

Fig. 2. Anterior nasal packing for epistaxis. 'Lubricated or antibiotic-soaked gauze was inserted into the anterior nasal cavity. ${ }^{2}$ Nasopharynx.

George Psillas et al: Epistaxis in dental and maxillofacial practice: a comprehensive review. J Korean Assoc Oral Maxillofac Surg 2022

severe epistaxis is angiography, which involves embolization of the internal maxillary artery (Fig. 1) and, in selected cases, the facial artery. With this technique, under general anesthesia and systemic heparinization, the femoral artery is punctured, and a catheter is used to catheterize both external carotid arteries and internal maxillary arteries. These vessels, which are responsible for epistaxis, are then embolized with microparticles $(300-500 \mu \mathrm{m})$ with success rates up to $97 \%{ }^{39}$.

\section{1) Dental implants}

Remarkable bleeding is often reported after implant placement, mainly in the mandible ${ }^{40}$. During therapeutic management, early attention should focus on evacuating local hematomas, identifying the damaged artery, and controlling the hemorrhage either with ligation or vessel cauterization. For cases where concomitant epistaxis is not conservatively controlled, a surgical technique involving maxillary sinus osteoplasty with a vascularized pedicle bone flap through a maxillary sinus approach has been reported ${ }^{8}$, wherein a horizontal incision in the upper vestibule was performed in front of the maxillary wall, a mucoperiosteal flap was raised, and a bony cut toward the inferior maxillary wall was made to provide access to the dental implant ${ }^{41}$. The bleeding site from the surrounding mucosal membrane and blood vessel were identified and effectively coagulated ${ }^{8}$. This intraoral method can replace endoscopic endonasal surgery, which can be challenging because of the acute angle from the middle or inferior nasal meatus to the bottom of the maxillary sinus, resulting in reduced visibility ${ }^{42}$.

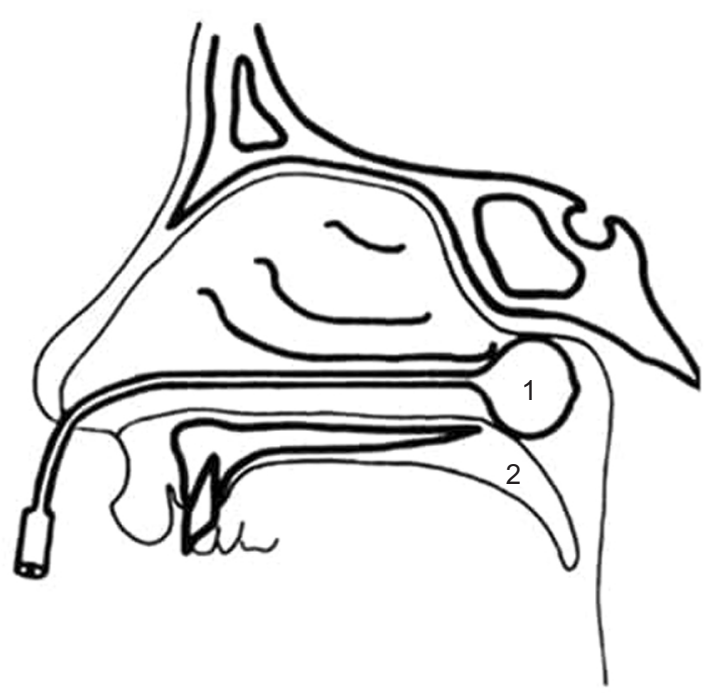

Fig. 3. Posterior nasal packing for posterior epistaxis using a ${ }^{1}$ Foley catheter balloon. ${ }^{2}$ Soft palate.

George Psillas et al: Epistaxis in dental and maxillofacial practice: a comprehensive review. J Korean Assoc Oral Maxillofac Surg 2022

\section{2) Osteotomy}

When epistaxis occurs after Le Fort I osteotomies, maxillomandibular fixation should be released, if used, to achieve a better intraoral view and to aspirate postnasal and pharyngeal clots. This allows the physician to estimate the degree of epistaxis severity. As in cases of active hemorrhage, vital signs should be monitored, an intravenous catheter should be placed ${ }^{13}$, and anterior and posterior nasal packing must be inserted into the nose to stop the bleeding. If postoperative epistaxis occurs early after surgery, a re-exploration should be considered; if bleeding occurs later or it is recurrent, angiography and subsequent embolization are indicated ${ }^{13}$. Mehra et al. ${ }^{14}$ reported a case of brisk epistaxis 11 days after a SARPE procedure, in which classical Le Fort I osteotomies were performed including pterygomaxillary separation without downfracturing the maxilla. Delayed epistaxis occurred but was managed successfully with posterior nasal packing via Foley catheters. The authors ${ }^{14}$ suggested surgical collapse of the expanded maxilla when adequate hemostasis was not achieved and epistaxis was not controlled after nasal packing because this could visualize the hemorrhage source in the maxilla and allow the pterygopalatine fossa to be tamponated more easily.

\section{3) Intranasal supernumerary tooth}

In a recent review ${ }^{43}$ of 23 studies, epistaxis was noted in six (22.2\%) of 27 patients, in which all these patients underwent $\mathrm{CT}$ scans to determine the location of intranasal teeth. The 
main approaches for tooth removal are intraoral and transnasal. The intraoral approach can harm neighboring teeth and damage the neurovascular bundle and oronasal fistulae ${ }^{23}$. Extraction of the intranasal tooth under endoscopic guidance has advantages of good illumination, clear visualization, and precise dissection with retained neighboring structures ${ }^{28}$. Total resolution of epistaxis and other symptoms was reported at 24 months after surgery ${ }^{43}$.

4) Dental care in patients with blood disorders

Patients with hemophilia are at high risk of intra- and postoperative epistaxis following dental procedures. Increasing factor VIII level for hemophilia A (factor IX for hemophilia B) and replacing factor VIII and inhibiting fibrinolysis (tranexamic acid) for patients undergoing dental or maxillofacial surgery are required ${ }^{30}$. Mechanical compression with vasoconstrictors and local hemostatic agents, such as collagen vials (Helistat), cellulose-based products (Tampotamp, Surgicel), fibrin glue (Tissucol), and resorbable sutures ${ }^{44}$, can be locally applied. Desmopressin (DDAVP) is used to increase factor VIII and can also be administered in von Willebrand's disease ${ }^{45}$.

For dental procedures, it is not necessary to modify antiplatelet therapy or vitamin $\mathrm{K}$ antagonists administered for primary or secondary cardiovascular disease prevention ${ }^{46}$. Moreover, novel oral anticoagulants have been developed to treat atrial fibrillation, pulmonary thromboembolism and venous thrombosis ${ }^{47}$. In a recent study ${ }^{47}$ of 153 cases prescribed novel oral anticoagulants, postoperative bleeding such as epistaxis occurred in only nine cases (two after scaling, three after simple extraction, three after first-stage implant surgery, one after resin filling). The authors reported that it is safe to perform most dental practices in patients taking these anticoagulants regardless of the anticoagulant's discontinuance duration; however, they postulated that dental and maxillofacial procedures requiring graft and osteotomy need at least 24 hours of discontinuance ${ }^{47}$. In cases of severe epistaxis, attempts to reverse anticoagulation or to cease anticoagulant therapy should be considered ${ }^{48}$. Idarucizumab is an antibody antigen-binding fragment that completely reverses the anticoagulant effect within minutes of administration ${ }^{48}$.

\section{5) Maxillofacial trauma}

Gentle in-depth placement of bilateral anterior nasal packing with Vaseline gauze is recommended for epistaxis, and more aggressive placement of a Foley catheter balloon for posterior epistaxis should be avoided to not aggravate any preexisting traumatic tearing or laceration of the nasal mucosa. Patients with severe or recalcitrant epistaxis might need cauterization-clipping of the sphenopalatine artery or ethmoidal arteries after lateral canthotomy (Lynch incision) ${ }^{35}$. Angiography-embolization of the internal maxillary artery and ethmoidal arteries should be last options in cases of intractable epistaxis.

\section{Discussion}

There have been many reported complications of intraoral bleeding episodes following dental interventions, but there is a lack of reviews assessing epistaxis resulting from dental and maxillofacial surgery. In our review, the main odontogenic causes leading to epistaxis were described, and general guidance for managing epistaxis was provided. The source of nasal bleeding can be located in the nasal cavity (intranasal supernumerary tooth, odontogenic tumor, nasal fracture), the maxillary sinus (dental implants), the oral cavity (dental procedures with blood disorders), or even the pterygomaxillary area (Le Fort osteotomy, maxillofacial trauma). However, epistaxis as an epiphenomenon should be treated in the same way regardless of bleeding site.

For slight epistaxis, the patient should be treated with rest, mild sedatives, and observation. Unless epistaxis stops, there is need for more definitive therapy, including nasal electrocautery or anterior and posterior nasal packing. Packing is not effective for major posterior epistaxis. At that point, depending on the location and extent of dental surgery, it is crucial to decide whether to reexplore the surgical site (after dental implant placement or Le Fort I osteotomy), especially if epistaxis occurs early in the postoperative period. Otherwise, invasive procedures, such as cauterization of the sphenopalatine artery under endonasal endoscopy or embolization of the internal maxillary artery, should be performed. It is widely debated whether endonasal cauterization-ligation of the sphenopalatine artery or embolization should be the first choice for intractable posterior epistaxis. In our center, we prefer sphenopalatine artery cauterization when epistaxis is not resolved by conservative treatment. However, for epistaxis after dental or maxillofacial procedures, such as dental implant and osteotomy procedures, angiography-embolization has the advantage of showing the hemorrhage site, allowing precise treatment (even if the patient is actively bleeding) ) $^{2,14,22}$. Moreover, as angiographic localization and embolization can be carried out at the same time, it is valuable to pinpoint ruptured pseudoaneurysms of the internal maxillary artery and to 
expose the collateral blood flow contributing to epistaxis ${ }^{13,18}$. Embolization of the bilateral internal maxillary artery or the ipsilateral facial artery can be performed without complications and no significant recurrent epistaxis and can also be performed in cases of maxilla trauma, odontogenic tumors, vascular abnormalities, and bleeding diathesis ${ }^{39}$.

Generally, in patients with bleeding disorders such as vascular defects, it is important to reinforce hemostasis during dental or maxillofacial surgery using local measures based on mechanical compression, suturing, and hemostatic agents (Surgicel, Gelfoam, gauzes) ${ }^{31}$. With platelet defects, the minimum blood platelet level before dental procedures is $50,000 / \mu \mathrm{L}$; for extensive procedures, it should be more than $100,000 / \mu \mathrm{L}$. Replacement therapy with platelet transfusion might be required 30 minutes before surgery ${ }^{30}$. For patients with coagulation disorders, the missing factor should be administered prior to surgery ${ }^{45}$. Dentists need to be informed of the potential severity of epistaxis and the increased likelihood of recurrence in patients taking oral anticoagulation therapy who are undergoing dental or maxillofacial interventions. Preoperative involvement of the hematologist and cardiologist is usually necessary to modify drug dosage ${ }^{48}$.

\section{ORCID}

George Psillas, https://orcid.org/0000-0003-3509-6519

Grigorios Georgios Dimas, https://orcid.org/0000-0001-8288-0723

Despoina Papaioannou, https://orcid.org/0000-0002-2108-9329

Christos Savopoulos, https://orcid.org/0000-0002-7970-2464

Jiannis Constantinidis, https://orcid.org/0000-0002-2849-356X

\section{Authors' Contributions}

G.P. participated in data collection and wrote the manuscript. G.P., G.G.D., and D.P. participated in the study design and performed the statistical analysis. C.S. and J.C. participated in the study design and coordination and helped to draft the manuscript. All authors read and approved the final manuscript.

\section{Conflict of Interest}

No potential conflict of interest relevant to this article was reported.

\section{References}

1. Morgan DJ, Kellerman R. Epistaxis: evaluation and treatment. Prim Care 2014;41:63-73. https://doi.org/10.1016/j.pop.2013.10.007

2. Solomons NB, Blumgart R. Severe late-onset epistaxis following Le Fort I osteotomy: angiographic localization and embolization. J Laryngol Otol 1988;102:260-3. https://doi.org/10.1017/ s0022215100104670

3. Krulewitz NA, Fix ML. Epistaxis. Emerg Med Clin North Am 2019;37:29-39. https://doi.org/10.1016/j.emc.2018.09.005

4. Tatum H Jr. Maxillary and sinus implant reconstructions. Dent Clin North Am 1986;30:207-29.

5. Ferguson M. Rhinosinusitis in oral medicine and dentistry. Aust Dent J 2014;59:289-95. https://doi.org/10.1111/adj.12193

6. Stacchi C, Andolsek F, Berton F, Perinetti G, Navarra CO, Di Lenarda R. Intraoperative complications during sinus floor elevation with lateral approach: a systematic review. Int J Oral Maxillofac Implants 2017;32:e107-18. https://doi.org/10.11607/jomi.4884

7. Alberti PW. Applied surgical anatomy of the maxillary sinus. Otolaryngol Clin North Am 1976;9:3-20.

8. Hong YH, Mun SK. A case of massive maxillary sinus bleeding after dental implant. Int J Oral Maxillofac Surg 2011;40:758-60. https://doi.org/10.1016/j.ijom.2010.11.027

9. Nooh N. Effect of schneiderian membrane perforation on posterior maxillary implant survival. J Int Oral Health 2013;5:28-34.

10. Kim HY, Yang JY, Chung BY, Kim JC, Yeo IS. Peri-implant bone length changes and survival rates of implants penetrating the sinus membrane at the posterior maxilla in patients with limited vertical bone height. J Periodontal Implant Sci 2013;43:58-63. https://doi. org/10.5051/jpis.2013.43.2.58

11. Shihab OI. Intentional penetration of dental implants into the maxillary sinus: a retrospective study. Zanco J Med Sci 2017;21:15369. https://doi.org/10.15218/zjms.2017.001

12. Bae OY, Kim YS, Shin SY, Kim WK, Lee YK, Kim SH. Clinical outcomes of reamer- vs osteotome-mediated sinus floor elevation with simultaneous implant placement: a 2-year retrospective study. Int J Oral Maxillofac Implants 2015;30:925-30. https://doi. org/10.11607/jomi.3779

13. Lanigan DT, Hey JH, West RA. Major vascular complications of orthognathic surgery: hemorrhage associated with Le Fort I osteotomies. J Oral Maxillofac Surg 1990;48:561-73. https://doi. org/10.1016/s0278-2391(10)80468-9

14. Mehra P, Cottrell DA, Caiazzo A, Lincoln R. Life-threatening, delayed epistaxis after surgically assisted rapid palatal expansion: a case report. J Oral Maxillofac Surg 1999;57:201-4. https://doi. org/10.1016/s0278-2391(99)90241-0

15. Williams BJ, Currimbhoy S, Silva A, O'Ryan FS. Complications following surgically assisted rapid palatal expansion: a retrospective cohort study. J Oral Maxillofac Surg 2012;70:2394-402. https://doi.org/10.1016/j.joms.2011.09.050

16. de Mol van Otterloo JJ, Tuinzing DB, Greebe RB, van der Kwast WA. Intra- and early postoperative complications of the Le Fort I osteotomy. A retrospective study on 410 cases. J Craniomaxillofac Surg 1991;19:217-22. https://doi.org/10.1016/s10105182(05)80551-7

17. Eshghpour M, Mianbandi V, Samieirad S. Intra- and postoperative complications of Le Fort I maxillary osteotomy. J Craniofac Surg 2018;29:e797-803. https://doi.org/10.1097/ SCS.0000000000004828

18. Avelar RL, Goelzer JG, Becker OE, de Oliveira RB, Raupp EF, de Magalhães PS. Embolization of pseudoaneurysm of the internal maxillary artery after orthognathic surgery. J Craniofac Surg 2010; 21:1764-8. https://doi.org/10.1097/SCS.0b013e3181f40393

19. Park B, Jang WH, Lee BK. An idiopathic delayed maxillary hemorrhage after orthognathic surgery with Le Fort I osteotomy: a case report. J Korean Assoc Oral Maxillofac Surg 2019;45:364-8. https://doi.org/10.5125/jkaoms.2019.45.6.364 
20. Garg S, Kaur S. Evaluation of post-operative complication rate of Le Fort I osteotomy: a retrospective and prospective study. J Maxillofac Oral Surg 2014;13:120-7. https://doi.org/10.1007/s12663012-0457-4

21. Niazi MH, El-Ghanem M, Al-Mufti F, Wajswol E, Dodson V, Abdulrazzaq A, et al. Endovascular management of epistaxis secondary to dissecting pseudoaneurysm of the descending palatine artery following orthognathic surgery. J Vasc Interv Neurol 2018;10:41-6.

22. Bykowski MR, Hill A, Garland C, Tobler W, Losee JE, Goldstein JA. Ruptured pseudoaneurysm of the maxillary artery and its branches following Le Fort I osteotomy: evidence-based guidelines. J Craniofac Surg 2018;29:998-1001. https://doi.org/10.1097/ SCS.0000000000004396

23. Krishnan B, Parida PK, Gopalakrishnan S, Satyparakash MV. An unusual cause of epistaxis in a young patient: the supernumerary nasal tooth. Oral Maxillofac Surg 2013;17:315-7. https://doi. org/10.1007/s10006-013-0393-6

24. Iwai T, Aoki N, Yamashita Y, Omura S, Matsui Y, Maegawa J, et al. Endoscopic removal of bilateral supernumerary intranasal teeth. J Oral Maxillofac Surg 2012;70:1030-4. https://doi.org/10.1016/ j.joms.2011.10.014

25. Verma RK, Bakshi J, Panda NK. Ectopic intranasal tooth: an unusual cause of epistaxis in a child. Ear Nose Throat J 2012;91:2424.

26. Al Dhafeeri HO, Kavarodi A, Al Shaikh K, Bukhari A, Al Hussain O, El Baramawy A. Recurrent epistaxis caused by an intranasal supernumerary tooth in a young adult. Am J Case Rep 2014;15:2913. https://doi.org/10.12659/AJCR.890710

27. Kirmeier R, Truschnegg A, Payer M, Malyk J, Daghighi S, Jakse N. The supernumerary nasal tooth. Int J Oral Maxillofac Surg 2009; 38:1219-22. https://doi.org/10.1016/j.ijom.2009.06.013

28. Lee FP. Endoscopic extraction of an intranasal tooth: a review of 13 cases. Laryngoscope 2001;111:1027-31. https://doi. org $/ 10.1097 / 00005537-200106000-00017$

29. Milam SB, Cooper RL. Extensive bleeding following extractions in a patient undergoing chronic hemodialysis. Oral Surg Oral Med Oral Pathol 1983;55:14-6. https://doi.org/10.1016/00304220(83)90298-0

30. Gupta A, Epstein JB, Cabay RJ. Bleeding disorders of importance in dental care and related patient management. J Can Dent Assoc 2007;73:77-83

31. Rafique S, Fiske J, Palmer G, Daly B. Special care dentistry: part 1. Dental management of patients with inherited bleeding disorders. Dent Update 2013;40:613-6, 619-22, 625-6 passim. https://doi. org/10.12968/denu.2013.40.8.613

32. Virupakshappa D, Rajashekhara BS, Manjunatha BS, Das N. Adenomatoid odontogenic tumour in a 20 -year-old woman. BMJ Case Rep 2014;2014:bcr2013010436. https://doi.org/10.1136/bcr-2013010436

33. Wenig BL, Sciubba JJ, Cohen A, Goldstein A, Abramson AL. An unusual cause of unilateral nasal obstruction: ameloblastoma. Otolaryngol Head Neck Surg 1985;93:426-32. https://doi. org/10.1177/019459988509300327

34. Kühnel TS, Reichert TE. Trauma of the midface. GMS Curr Top Otorhinolaryngol Head Neck Surg 2015;14:Doc06. https://doi. org/10.3205/cto000121

35. Dallan I, Tschabitscher M, Castelnuovo P, Bignami M, Muscatello L, Lenzi R, et al. Management of severely bleeding ethmoidal arteries. J Craniofac Surg 2009;20:450-4. https://doi.org/10.1097/ SCS.0b013e31819b9803

36. Yonezawa H, Yanamoto S, Hoshino T, Yamada S, Fujiwara T, Umeda M. Management of maxillary alveolar bone fracture and severely intruded maxillary central incisor: report of a case. Dent Traumatol 2013;29:416-9. https://doi.org/10.1111/j.16009657.2011.01111.x

37. Pashen D, Stevens M. Management of epistaxis in general practice. Aust Fam Physician 2002;31:717-21.

38. Kitamura T, Takenaka Y, Takeda K, Oya R, Ashida N, Shimizu K, et al. Sphenopalatine artery surgery for refractory idiopathic epistaxis: systematic review and meta-analysis. Laryngoscope 2019; 129:1731-6. https://doi.org/10.1002/lary.27767

39. Shah QA. Bilateral tri-arterial embolization for the treatment of epistaxis. J Vasc Interv Neurol 2008;1:102-5.

40. Tomljenovic B, Herrmann S, Filippi A, Kühl S. Life-threatening hemorrhage associated with dental implant surgery: a review of the literature. Clin Oral Implants Res 2016;27:1079-84. https://doi. org $10.1111 /$ clr. 12685

41. Lazaridis N, Tilaveridis I, Venetis G, Lazaridou M. Maxillary sinus osteoplasty with vascularized pedicled bone flap. Oral Surg Oral Med Oral Pathol Oral Radiol Endod 2008;106:828-32. https://doi. org/10.1016/j.tripleo.2008.05.030

42. Aukštakalnis R, Simonavičiūte R, Simuntis R. Treatment options for odontogenic maxillary sinusitis: a review. Stomatologija 2018; 20:22-6.

43. Levin M, Sommer DD. Endoscopic removal of ectopic sinonasal teeth: a systematic review. J Otolaryngol Head Neck Surg 2019;48:30. https://doi.org/10.1186/s40463-019-0353-8

44. Peisker A, Raschke GF, Schultze-Mosgau S. Management of dental extraction in patients with haemophilia A and B: a report of 58 extractions. Med Oral Patol Oral Cir Bucal 2014;19:e55-60. https:// doi.org/10.4317/medoral.19191

45. Anderson JA, Brewer A, Creagh D, Hook S, Mainwaring J, McKernan A, et al. Guidance on the dental management of patients with haemophilia and congenital bleeding disorders. Br Dent J 2013; 215:497-504. https://doi.org/10.1038/sj.bdj.2013.1097

46. Dézsi CA, Dézsi BB, Dézsi AD. Management of dental patients receiving antiplatelet therapy or chronic oral anticoagulation: a review of the latest evidence. Eur J Gen Pract 2017;23:196-201. Erratum in: Eur J Gen Pract 2017;23:i-ii. https://doi.org/10.1080/13 814788.2017.1350645

47. Kwak EJ, Nam S, Park KM, Kim SY, Huh J, Park W. Bleeding related to dental treatment in patients taking novel oral anticoagulants (NOACs): a retrospective study. Clin Oral Investig 2019;23:47784. https://doi.org/10.1007/s00784-018-2458-2

48. Ho JPK, Bari N, Riffat F. Management of epistaxis in patients on novel oral anticoagulation therapy. J Laryngol Otol 2020;134:31622. https://doi.org/10.1017/S0022215120000754

How to cite this article: Psillas G, Dimas GG, Papaioannou D, Savopoulos C, Constantinidis J. Epistaxis in dental and maxillofacial practice: a comprehensive review. J Korean Assoc Oral Maxillofac Surg 2022;48:13-20. https://doi.org/10.5125/jkaoms.2022.48.1.13 